\title{
ESTUDO de FALHAS em MÁQUINAS VIRTUAIS no AMBIENTE de
} NUVEM

\author{
Ricardo T. Manoel Junior (IC), Regina L. O. Moraes (PQ)
}

\begin{abstract}
Resumo
O projeto propõe o estudo das falhas relacionadas à virtualização do ambiente de nuvem, possibilitando a compreensão da propagação das mesmas e seu impacto sobre os serviços e dados gerenciados pela Máquina Virtual, bem como sua exploração em tentativas de invasão ao ambiente. Através de técnicas de cargas de trabalho, foi realizada a análise do comportamento do sistema sob a presença de falhas.
\end{abstract}

Palavras Chave: Computação em Nuvem, Estudos de Falhas, Testes de Carga.

\section{Introdução}

A computação em nuvem é uma tecnologia originada em função da evolução do conceito de Internet. A nuvem representa a Internet no contexto do projeto de redes de computadores (VELTE et al., 2009). Do ponto de vista de um usuário, a nuvem é um serviço, contratado de um provedor. Contanto que o provedor forneça um serviço minimamente qualificado, o usuário não precisa se importar com a estrutura de apoio.

As VMs são responsáveis pelo processo de encapsulamento de cada ambiente da nuvem, proporcionando independência entre ambientes de usuários distintos. Embora essa independência aumente a segurança e a qualidade do serviço, as VMs não são totalmente isentas de falhas. Dessa forma, o projeto visa identificar e analisar falhas que são pertinentes ao ambiente virtualizado e entender 0 impacto da sua ativação nesse ambiente.

Uma aplicação que emula a carga de trabalho no ambiente de nuvem foi utilizada e um monitoramento foi feito para entender como o ambiente escala para um número maior de usuários sob alta carga de trabalho, analisando o impacto na qualidade do serviço.

\section{Resultados e Discussão}

Foram utilizadas duas ferramentas para operações com a nuvem. A primeira, o serviço de nuvem elástica da Amazon, o Amazon Elastic Compute Cloud (Amazon EC2). O EC2 permite aos usuários, de forma flexível alugar recursos computacionais para uso por suas aplicações. Para os casos de testes foi utilizada a Imagem de Máquina Virtual (AMI) padrão do EC2 com um servidor Apache pré-configurado.

A segunda ferramenta, o Loadlmpact emula o teste de carga, projetado para aplicações moveis, interface de programação, sites e servidores. A carga criada pelo Loadlmpact, emulando 50 usuários com uso durante 5 minutos, foi submetida às AMls configuradas na categoria de micro a extra grande. O desempenho das VMs foi observado em relação ao crescimento do número de usuários virtuais (VU), tempo de carga dos usuários virtuais, falhas de perda de pacote e jitter. A Figura 1 apresenta um gráfico que mostra 0 comportamento da VM em presença dessas falhas.

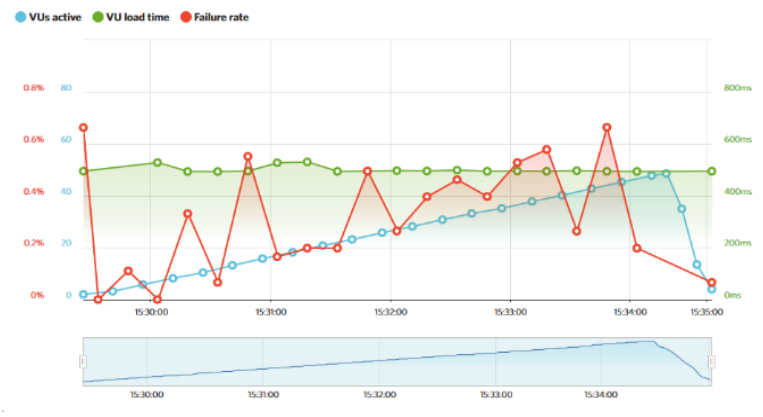

Figura 1. Desempenho da VM em presença de falhas de perda de pacote e jitter

Percebe-se que no gráfico apresentado pela Figura 1, o desempenho da VM não é impactado nem pelo aumento no número de usuários virtuais nem pela taxa de falhas a que foi submetida, apresentando um tempo estável de carga durante o experimento.

\section{Conclusões}

O trabalho propôs o estudo de falhas em ambientes virtualizados. A criação de máquinas virtuais na nuvem é bastante facilitada pelo uso das imagens (AMIs). Embora o uso em aplicações reais seja necessário uma configuração específica (principalmente por aspectos de segurança), nesse estudo fizemos a avaliação da VM criada pela AMI padrão do Amazon EC2. Foram utilizadas várias configurações do EC2 (de micro a extra grande) e, com o numero de VU máximo permitido (50 VUs) não foram observados impactos negativos no tempo de carga da VM, apresentando-se robusta à escala de VUs e às falhas de perda de pacote e jitter.

Agradecimentos

Os autores agradecem o programa $\mathrm{PIBIC/CNPq}$ pelo apoio à pesquisa.

VELTE, T.; VELTE, A.; ELSENPETER, R. Cloud computing: a practical approach. [S.1.]: McGraw-Hill Osborne Media, 2009. 